\title{
Davina Cooper: Everyday Utopias: The Conceptual Life of Promising Spaces
}

\author{
Duke University Press, Durham and London, 2014, 296 pp, \\ ISBN: 978-0-8223-5569-4
}

\section{Will Odogwu}

Published online: 23 January 2015

(C) The Author(s) 2015. This article is published with open access at Springerlink.com

Utopian studies can be reawakened to its transformative possibilities by taking seriously the conceptual contributions latent in everyday efforts to live life differently. This is what Davina Cooper seeks to demonstrate in her theoretically innovative encounter with six sites in which people strive to actively live out or 'actualise' utopian visions in everyday contexts. The sites selected are an eclectic grouping. Britain's government-led equality drive of the years 2009-2010 is explored in chapter 3. Nudism and nudist organisations come under the lens in chapter 4, while chapter 5 directs attention to a casual sex venue, the Toronto Women's and Trans Bathhouse (TWTB). In chapter 6 the alternative currencies initiatives championed in Local Exchange Trading Schemes are examined. The final two chapters guide readers through an imaginative conceptual understanding of practices at Summerhill School (chapter 7) and Hyde Park's Speakers' Corner (chapter 8).

In looking at these 'everyday' utopias, Cooper seeks to move the focus away from literary visions of all-encompassing, radical, dream-like transformations of entire societies. She chooses instead to turn toward sites where utopian aspirations are actually put into practice, albeit on smaller scales and in less comprehensive ways. 'Everyday,' in Cooper's usage, further connotes that participants are, alongside their utopian project involvement, still occupied in the ongoing maintenance of lives or functions that are embedded in the larger scale social institutions of mainstream society. These practical utopias therefore constitute parttime, episodic, or otherwise temporally limited 'minor stream' practices. What attracts Cooper to these spaces is the conviction that they constitute fertile sites for

\footnotetext{
W. Odogwu $(\bowtie)$

SOAS, University of London, London, UK

e-mail: 605358@soas.ac.uk

W. Odogwu

University of Warsaw, Warsaw, Poland
} 
developing (or finding) innovative re-conceptualisations of many concepts in common currency. Through the circulation of the new understandings of such concepts other spheres of life might be enriched or unsettled.

At the heart of the study looms the notion of the 'concept' and the elaboration of Cooper's concept of the concept, as it were, is the main task pursued in the book's first two chapters - though it is further advanced in later chapters where relevant context lends itself to this task (see e.g. 126-128). The dipole of 'imagining and actualisation' is the dominant theme in Cooper's approach to concepts. Concepts are posited as the "oscillating movement between imagining and actualisation" (11). Although this might at first appear to suggest only that it is in the course of such movements that concepts are formed, it gradually emerges that Cooper is arguing for more than this. Concepts, in this view, are not 'entities' capable of being formed in any final or even provisional sense, whether within movements or anywhere else; rather it is suggested that concepts constitute the very flow by which we get ourselves from imagining to actualisation and vice versa.

In this vision, concepts are no longer exclusively, or even primarily, intellectual constructs. In parallel with the approaches adopted by such authors as Nicholas Gane (2009: 86) and Ruth Levitas (2013), Cooper seeks to emphasise the importance of ineffable experiences. Yet in contrast to those approaches, which situate these experiences in the 'pre-conceptual,' we find ineffable experience being brought inside the understanding of what concepts are or perhaps should be. Cooper stresses that regarding such domains of "knowledge and understanding [that] exceed understanding" as merely playing a role in conceptual emergence, for example as triggers provoking conceptualising responses, misses the mark. On this basis, neither emotive reaction and expression, nor sensations and actions can be distinguished from conceptual work.

Equally important to Cooper's approach is the emphasis on the bi-directional and continuous nature of the imagination-actualisation connection: concepts, themselves fluid and restless, are inevitably always feeding into both new actualisations and new imaginings, as these are simultaneously also rebounding back on concepts and maintaining their mutual interaction through concepts (36). Cooper's concepts therefore seem not to be susceptible to straightforward instrumental use by agents, but nor are they natural forces working their way inevitably through life cycles determined by their internal logics. Drawing on Bruno Latour's work, Cooper instead envisions 'mediators,' in the sense of actors or institutions that perform nonlinear forms of transmission (Latour 2005: 58), interrupting any attempt to predict the development of conceptual life or otherwise contain it. Cooper casts this lack of predictability in positive terms however, noting that it provides "the generative ground through which concepts develop, change, thrive, get stuck, and carry power." (40)

In adopting this theoretical position Cooper is, at least in part, motivated by normative concerns. By envisioning concepts as oscillating processes, the stress is placed on their always elusive, fluid and improvisational-tactical quality. Additionally, through bringing the concept into the world of social practices (and vice versa), Cooper is anxious to liberate concepts from the exclusive claims of 'history of ideas' inspired approaches. The argument is that such methods risk deadening the 
development of conceptual life, as exegesis of the scholarly texts of the past becomes accepted as indispensable to accessing the range of 'authentic' present meanings of specific concepts. A reconnection with the well-springs of lived experience is sought. Even if one were to depart from the view that the achievement of this requires the incorporation of 'practice' and 'feeling' inside our understanding of the concept (as opposed to, for example, seeing these domains as indispensible to the processes of conceptual formation), it is easy to agree with the high value Cooper attributes to the reestablishment of this type of vital connection. The imaginative possibilities of Cooper's approach, particularly when the connections sought are with 'minor stream' life, are emphatically brought home to the reader by the almost endlessly creative conceptualisation that characterises much of Everyday Utopias.

Nevertheless, the formula of Cooper's success cannot be understood without also incorporating here the distinction drawn in the book between different spheres of conceptual activity with a view to identifying the most productive possibilities. I will focus on elucidating this key distinction and in the process make illustrative use of examples drawn from the book's treatment of specific utopian spaces.

Everyday Utopias deliberately directs our attention to those concepts which are not integrated into the self-conceived raison d'être of the various progressive spaces. Rather, the concepts of interest are those incidentally pulled into play as the actualisation of the imperatives of the relevant dominant utopian ideal lead to engagements with other normative concepts. These off-centre concepts could, Cooper writes, be thought of as 'oblique' or even 'queer' conceptual lines. Here Cooper herself refers the reader forward to some of the conceptual juxtapositions she pursues in later chapters, noting that the Summerhill School will be considered in relation to the concept of property rather than freedom, while the chapter on equality governance follows lines traced by the concept of touch, not discrimination. By no means, however, are such locally dominant themes as freedom and discrimination excluded from discussion as a result; it is simply that they are approached through oblique conceptual angles.

As Cooper explains, the benefits of such an approach are at least threefold. First, it serves to draw attention to "the manifold things such sites do, beyond their headline contribution" (14). Indeed, Cooper probes Speakers' Corner (chapter 8) from the vantage point of the insights it may produce for our understanding of markets, and particularly 'markets to play.' This leads to unexpected avenues of development as Cooper moves first through familiar market-related tropes such as the 'marketplace of ideas,' and then onwards to different types of pleasurable and stimulating markets manifested at the Corner. These markets enact the competitive fun of games or the ambiguity and mockery of carnivals (220-225), the education of taste and desire as attendees browse and sample from the discourses on offerdeveloping their evaluative expertise in the process (205-208), and the enjoyable challenge of 'edgework' found in the carefully ventured self-exposure arising out of risky exchanges taken to a place just short of loss of control (210-213).

As this example suggests, besides opening our eyes to the range of conceptual innovation going on within sites, an interrogation of oblique concepts also allows us to draw perhaps unexpected connections between such everyday utopian sites and 
other spheres of social life, thereby opening the way to "different forms of imagining" that could "unsettle wider commonsense assumptions about what concepts mean and how they operate" (14). Cooper pursues a strategy of exactly this sort when she examines the possible significance of the participant experiences and the practices developed at the TWTB for what she argues is as an increasingly rigidified concept of feminist care ethics (FCE) (101). TWTB is shown to throw up doubts about the one-dimensional perception of needs as naturalised phenomena (116), the generally negative valorisation of vulnerability (as always something to be managed and minimised) (117), and the possible desirability of creating and encouraging particular kinds of needs, particularly in a space which participants view as helping "women and trans people develop more sexually confident subjectivities" (118). It is not that Cooper suggests that FCE must always exhibit these antinomies in all contexts, but troubling its assumed content through exposure to unfamiliar contexts has the benefit of opening FCE to re-imaginings.

Finally, Cooper maintains that, insofar as oblique concepts do not figure prominently or at all in the directly expressed goals of the utopian spaces in question, "imagining and actualisation do not converge" (14). The attendant instability has its flip-side in versatility. Like veritable conceptual stem-cells, concepts performing in such unstable ways "hold out the most potential to develop in multiple, new ways" (ibid.). This can be illustrated through exploring Cooper's re-imaginings of the concept of property, a concept not traditionally noted for its progressive potential or instability. The site from which these re-imaginings are drawn is that of the Summerhill School (chapter 7). Property's oblique relation to the more obvious centres of the School's conceptual self-understanding, such as freedom, provides a certain distance from the discourses and practices traditionally dominating the enactment of property's conceptual lines. As a result, Cooper finds possibilities for opening up new paths.

As Cooper expands on the notion of 'property as belonging,' she teases out the ways in which ideas of belonging as a "constitutive relationship" or a relationship of "proper attachment" (162) can be seen through Summerhillian practice to find elucidation in, and in turn to open up, some aspects of conventional 'bundle of rights' conceptions of property. Constitutive or "part-whole" belonging refers to the "dynamic and mutually formative" (ibid.) way in which children belong to families, gardens belong to houses, or citizens belong to nations "where the formation of each [identity] is dependent on the relationship itself" (ibid.). Attachment connotes something similar, but references more directly the sense of people or things as belonging with certain others. For example, a child might be said to belong with its mother. Political projects might promote forms of proper attachment belonging also, such as campaigns for gay relationship recognition seeking to "generate counter-normative versions of the 'we' that belong (legally, socially, emotionally) together" (163).

Through the practice of Summerhill School, Cooper brings these 'belongings' and 'property' closer together. For example, Cooper discusses how responsibilities and rights of 'stewardship' follow on from being a Summerhillian (175-176). In the words of the school's principal, Zoe Readhead, as a result of this sensed belonging the children "will defend the laws [of school governance] and they take on 
responsibilities beyond what they would like to do" (176). Yet, rights reminiscent of a more mainstream conception of property are also manifest in the decision-making power wielded by the children through this belonging. Cooper relates a striking example in which a school meeting of children and staff was held during an adjournment in High Court proceedings affecting the school in order to determine jointly whether to accept a settlement proposed by the government (ibid.).

Ending on this example serves to emphasise perhaps the central strategic merit that can be claimed for Cooper's overall approach in Everyday Utopias. Rather than restricting utopian debates to, for example, discussion in terms of whether property should be abolished, restricted to private or public forms, or distributed in this manner or that, the approach which characterises this book seeks-through practices already ongoing in everyday utopias - to re-imagine concepts such as property in ways which might prove to be more supportive of progressive-transformative change more generally. Cooper does not assume that long-rehearsed conceptual lines will be radically challenged all at once or that alternatives will be free of problematic implications. But she does advocate and highlight a theoretical approach that elevates the practical experiences of everyday utopias into resources providing possibilities for the gradual opening up of such conceptual lines. These possibilities are envisioned as arising out of confrontation between the actualisations and imaginings mainstream conceptual lines presuppose and those which are usually beyond our view.

Open Access This article is distributed under the terms of the Creative Commons Attribution License which permits any use, distribution, and reproduction in any medium, provided the original author(s) and the source are credited.

\section{References}

Gane, Nicholas. 2009. Concepts and the 'new' empiricism. European Journal of Social Theory 12(1): 83-97.

Latour, Bruno. 2005. Reassembling the social: An introduction to actor-network theory. Oxford: Oxford University Press.

Levitas, Ruth. 2013. Utopia as method: The imaginary reconstitution of society. London: Palgrave Macmillan. 